\title{
KRAS NP_004976.2:p.Q61D
}

National Cancer Institute

\section{Source}

National Cancer Institute. KRAS NP 004976.2:p.Q61D. NCI Thesaurus. Code C98423.

A change in the amino acid residue at position 61 in the GT Pase KRas protein where glutamine has been replaced by aspartic acid. 